\title{
Accessibility of Assistive Software Installation Interfaces
}

\author{
Lucia Filgueiras $^{1}$, Edson Sales ${ }^{1}$, Lucy Gruenwald ${ }^{2}$, Ana Maria Barbosa ${ }^{2}$, \\ and Renato Facis ${ }^{3}$ \\ ${ }^{1}$ Escola Politecnica da Universidade de Sao Paulo, Sao Paulo, Brazil \\ ${ }^{2}$ Rede Saci, Sao Paulo, Brazil \\ ${ }^{3}$ LabIHC, Prodesp, Sao Paulo, Brazil \\ \{lucia.filgueiras, edson.sales\}@poli.usp.br, lucygru@ciblis.net, \\ ana@saci.org.br, rfacis@sp.gov.br
}

\begin{abstract}
Software installation is a one-time task; yet, it should work well. Regarding assistive technologies, users with disabilities will often require help in installation tasks. Five assistive software products were evaluated in order to identify barriers faced by visually impaired users performing the installation task and none of them, for different reasons, allowed full completion of installation task. Some recommendations are devised from the experience.
\end{abstract}

Keywords: Assistive technology, accessibility, installation software, usability.

\section{Introduction}

Assistive technology is fundamental for allowing people with disabilities to use computers in their daily life. Several studies have been devoted to assistive technologies and a few of them were focused on the usability of assistive software [1]. Traditionally, the largest part of the development effort - and nowadays, also of the usability effort - has been assigned to the core application functionalities. Online help, user documentation, installation and uninstallation interfaces were always seen as secondary in this development. This is not different with assistive technologies.

This paper reports the findings of usability evaluations performed on five assistive software tools, and focuses on the user experience with the installation interface. Section 2 presents issues about installation interfaces. Section 3 presents the evaluated assistive software products. Section 4 reviews the method and results obtained.

\section{Installation Interface Usability}

Installation interfaces peculiarities have motivated little research to the moment [2], [3]. Installation and uninstallation software is considered part of user documentation, according to IEEE Std 1063 [4].. Seffah and Metzker regretted that "developers with any HCI background, unfortunately by ignorance, are asked to develop software artifacts that we know have a direct impact on usability including help systems, training plans and resources, user documentation, technical support as well as installation and configuration procedures." [5] 
Installation procedures are often performed with the help of wizards, so that most of the necessary configuration tasks are hidden from the user in the typical process. When installation cannot follow the typical path, it tends to be a very complex activity that may require lots of work [6].

Rhodes [7] developed a case study of the installation interface of widely used commercial software. He summarized his painful experience in the following learned lessons: (1) Installation can take a lot of time; (2) Users are often forced to reboot their machines many times; (3) Users are often given very little control over the installation process; (4) Users are not given good information about the installation process; (5) Users are forced to buy software that is painful to install.

Consequences of bad installation software are the same ones of all other kinds of unusable software: user dissatisfaction, high costs due to user time and errors, high support cost and even total rejection. Lack of usability in installation interfaces has one additional major consequence that is the fact that poorly installed software will result in problems in regular use. Regarding ATs, this can be very disturbing, because this technology is a precondition to provide access to all other computer features.

\section{Installing Assistive Technologies}

Some disabilities require the person employ some form of assistive technology (AT) in order to make use of a computer. W3C accessibility rules and other for instance, presume the user is navigating with the aid of an AT. This is also the case of Leporini and Paternò work on [8].

This paper is focused on AT implemented as software products which can be installed on a computer in order to assist users with disabilities in the general use of a computer. There are several commercial alternatives of AT, and as a software product they must be submitted to usability evaluation.

AT usability is very important because a user with disability interacts with two different systems - the AT and the system being used. Both interaction languages must be taken into account when evaluating the disabled user's experience.

Even though AT development has cared for users' needs, some developers have not considered the scenario of getting started with the product. Whatever their reason is, total accessibility requires that the user can perform autonomously all desired tasks. Particularly, if the user with disability cannot perform the very first interaction step, for him or her all effort in accessibility will have been wasted.

Five AT products available in Brazil have been evaluated, regarding usability and accessibility of installation procedures. All products are available to the user, either for free or commercially sold. They were designed as assistance to visual impaired and blind users; however, they are known to have broader application, for instance, by elder people and by users with cognitive impairment. Some of their characteristics are summarized in the following items:

- AT1 is an operational system shell with a voice synthesizer and browser for internet access. It was developed by a Brazilian university team and is free.

- AT2 is a screen reader that enables access to Windows ${ }^{\circledR}$ applications. AT2 can be obtained freely for personal use but companies are required to pay. 
- AT3 is also a screen reader for Windows ${ }^{\circledR}$ applications. This product has been localized for Brazilian Portuguese and its license is sold.

- AT4 is a Web application to help people with low vision. It has a voice synthesizer and other resources to improve legibility of screen text.

- AT5 is another solution for people with low vision with some resources to facilitate the visualization and reading of Internet pages.

\section{Evaluation Method and Results}

All AT installation procedures were evaluated in usability experiments, with five visually impaired users. Three of them were blind; two had low vision. All were daily users of the internet and three of them worked in computer-related professions. All but one had experimented at least one AT before. Computer illiterate users were excluded from the user population because the installation task is too complex for a beginner and would place an unnecessary burden on these users.

Users were given a narrative that explained the experiment scenario: they had received a publication which gave directions on how to obtain AT products and they intended to try the ones they were not acquainted with. In order to do so, they would have to obtain, install and test them. Scenario had all information needed in order to obtain the tool. They could choose their favorite AT to drive the use and were given time to customize it to start the process, if they needed it. Observers would consider the task completed when the user initiated the obtained AT.

As the objective of this paper is to present barriers found in AT installation interfaces, only qualitative findings are presented in this section, regardless of which AT caused the issue.

None of the five AT were successfully installed by any of the selected users. The following paragraphs summarize the relevant barriers to installation.

1. Absence of voice synthesizers in the installation interface. Four of the five tested assistive technologies offer a voice synthesizer. However, some ATs do not employ this resource in the installation interface. Without the auditory feedback, blind users get uncertain if the process has succeeded.

2. Two ATs seldom coexist. In our experiments, users installed ATs with the help of their favorite one, which resulted in configuration conflicts and error messages. In some cases two AT voices spoke at the same time, none of them being understood.

3. Inaccessible essential information. One of the ATs had complete user documentation in Braille; however, the software key was in a small printed label inside the package. The Braille documentation did not inform about the label as part of the package.

4. Transition from installation to product use. Generally, installation finishes by leaving a shortcut for the application. Some ATs, besides doing that, also activate the application and move the focus to its window, leaving the user unaware of the change.

5. Inaccessible instructions. Four of the five AT had on-line user instructions on installation. Only one of them had a Braille manual. This obliged the user to use another AT to access the manuals and to ask for human help. 
6. Inconsistent information. User documentation referred to signs and symbols that were different from the ones actually used in the application.

Our experiments confirmed Rhodes learnt lessons for installation software and taught us some more specific ones about AT:

- AT installation interfaces must address the user they are intended for. If ablebodied assistance or special training is required to install the software, this should be stated clearly in the user documentation, again in an accessible manner.

- Users must be in control during all installation process and after it. If their actions are required, such as rebooting the computer, answering to error messages or activating the installed application, they must be aware of what they have to do, the reasons why and the consequences of not doing.

- AT installation interfaces should deal with the fact that the user may be using another similar product and avoid all kinds of conflicts.

- Software installation is considered a risky endeavor. Loss of situational awareness due to unanticipated and unannounced automatic actions should be avoided.

\section{Conclusion}

Assistive technologies are essential for digital inclusion of thousands of people with some form of disability. Users with disabilities are compelled to use awkward technology because they are in need of it and have few alternatives.

However, AT like any software product must be developed and evaluated considering a broad scope of the user experience with the tool - from installation to support. For some users with disabilities, having to ask for help is very frustrating.

\section{References}

1. Suttcliffe, A., Fickas, S., Sohlberg, M., Ehlhardt, L.: Investigating the usability of assistive user interfaces. Interacting with Computers 15 (2003)

2. Yeats, D.: Revising documentation deliverables based on usability evaluation findings: a case study. In: Proceedings of ACM SIGDOC'04, pp. 17-18. ACM Press, New York (2004)

3. Nichols, D.M., Twidale, M.B.: The usability of open source software. First Monday, vol. 8, n.1 (2003), http://firstmonday.org/issues/issue8_1/nichols/index.html

4. The Institute of Electrical and Electronics Engineers, IEEE Standard for Software User Documentation, IEEE Std 1063 (2001)

5. Seffah, A., Metzker, E.: The obstacles and myths of usability and software engineering. Communications of the ACM 47(12), 71-76 (2004)

6. Crawford, V., Pitts, A., Radcliffe, R., Seifert, L.A.: Solution documentation. In: Proceedings of ACM SIGDOC'04, pp. 72-74. ACM Press, New York (2004)

7. Rhodes, J.R.: Installing Norton Antivirus 2002: a usability case study. WebWord Newsletter (2002), http://www.webword.com

8. Leporini, B., Paternò, F.: Increasing usability when interacting through screen readers. Universal Access in the Information Society. Springer, Heidelberg (2004) 